\title{
Innate Immune Detection of Cardioviruses and Viral Disruption of Interferon Signaling
}

\author{
Eric C. Freundt ${ }^{1}$, Melissa Drappier ${ }^{2}$ and Thomas Michiels ${ }^{2 *}$ \\ ${ }^{1}$ Department of Biology, The University of Tampa, Tampa, FL, United States, ${ }^{2}$ de Duve Institute, Université catholique de \\ Louvain, Brussels, Belgium
}

Cardioviruses are members of the Picornaviridae family and infect a variety of mammals, from mice to humans. Replication of cardioviruses produces double stranded RNA that is detected by helicases in the RIG-I-like receptor family and leads to a signaling cascade to produce type I interferon. Like other viruses within Picornaviridae, however, cardioviruses have evolved several mechanisms to inhibit interferon production. In this review, we summarize recent findings that have uncovered several proteins enabling efficient detection of cardiovirus dsRNA and discuss which cell types may be most important for interferon production in vivo. Additionally, we describe how cardiovirus proteins $\mathrm{L}, 3 \mathrm{C}$ and $\mathrm{L}^{*}$ disrupt interferon production and antagonize the antiviral activity

OPEN ACCESS

Edited by:

Penghua Wang,

University of Connecticut Health

Center, United States

Reviewed by:

Aaron T. Irving,

Duke-NUS Medical School,

Singapore

Hiroyuki Oshiumi,

Kumamoto University, Japan

*Correspondence:

Thomas Michie/s

thomas.michiels@uclouvain.be

Specialty section:

This article was submitted to

Virology,

a section of the journal

Frontiers in Microbiology

Received: 05 July 2018

Accepted: 25 September 2018

Published: 12 October 2018

Citation:

Freundt EC, Drappier $M$ and Michiels T (2018) Innate Immune Detection of Cardioviruses and Viral

Disruption of Interferon Signaling.

Front. Microbiol. 9:2448.

doi: 10.3389/fmicb.2018.02448 of interferon effector molecules.

Keywords: cardiovirus, picornavirus, interferon, dsRNA, innate, RNase L, PKR, MDA5

\section{INTRODUCTION}

Picornaviridae is an important family of single-stranded, positive-polarity RNA viruses that includes $>30$ genera with over 75 species (Zell et al., 2017). Within Picornaviridae, the genus Cardiovirus includes encephalomyocarditis virus (EMCV), Theiler's murine encephalomyelitis virus (TMEV) and Saffold viruses (SAFV). Although EMCV has been described as a potential zoonotic agent, SAFVs are the only cardioviruses known to regularly infect humans, with the vast majority of people showing evidence of infection (Zoll et al., 2009; Carocci and Bakkali-Kassimi, 2012). EMCV has been found to infect over 30 host species and contains one serotype, Mengo virus, which was isolated in 1948 in the Mengo district of Uganda (Dick et al., 1948). TMEV was discovered in 1937 by Max Theiler and is found in wild mice and rats worldwide. TMEV can cause different diseases, depending on the virus strain and host genetics, ranging from fatal encephalitis to a chronic demyelinating disease that has served as a model for multiple sclerosis (Brahic et al., 2005).

The genome of cardioviruses is approximately $7.8-8.5 \mathrm{~kb}$ and contains $5^{\prime}$ and $3^{\prime}$ untranslated regions (Figure 1). Translation of the genome gives rise to a polyprotein that is cleaved by the $3 \mathrm{C}$ protease, leading to the production of 12 proteins. Two additional proteins, $\mathrm{L}^{*}$ and $2 \mathrm{~B}^{*}$, are expressed from alternate open reading frames. $\mathrm{L}^{*}$ is only expressed by TMEV and is important for infection of macrophages, persistence of the virus in mice and inhibiting RNase L (van Eyll and Michiels, 2000; Sorgeloos et al., 2013), 2B* results from a frameshifting mechanism conserved in cardioviruses that regulates the ratio of structural and non-structural proteins translated over time. Protein $2 \mathrm{~B}^{*}$ itself is only thought to be important for replication of EMCV, as mutants that abolish its expression had a small plaque phenotype. $2 \mathrm{~B}^{*}$ in TMEV and SAFV is unlikely to act as a protein as it is predicted to encode a peptide of 14 amino acids (Loughran et al., 2011). 

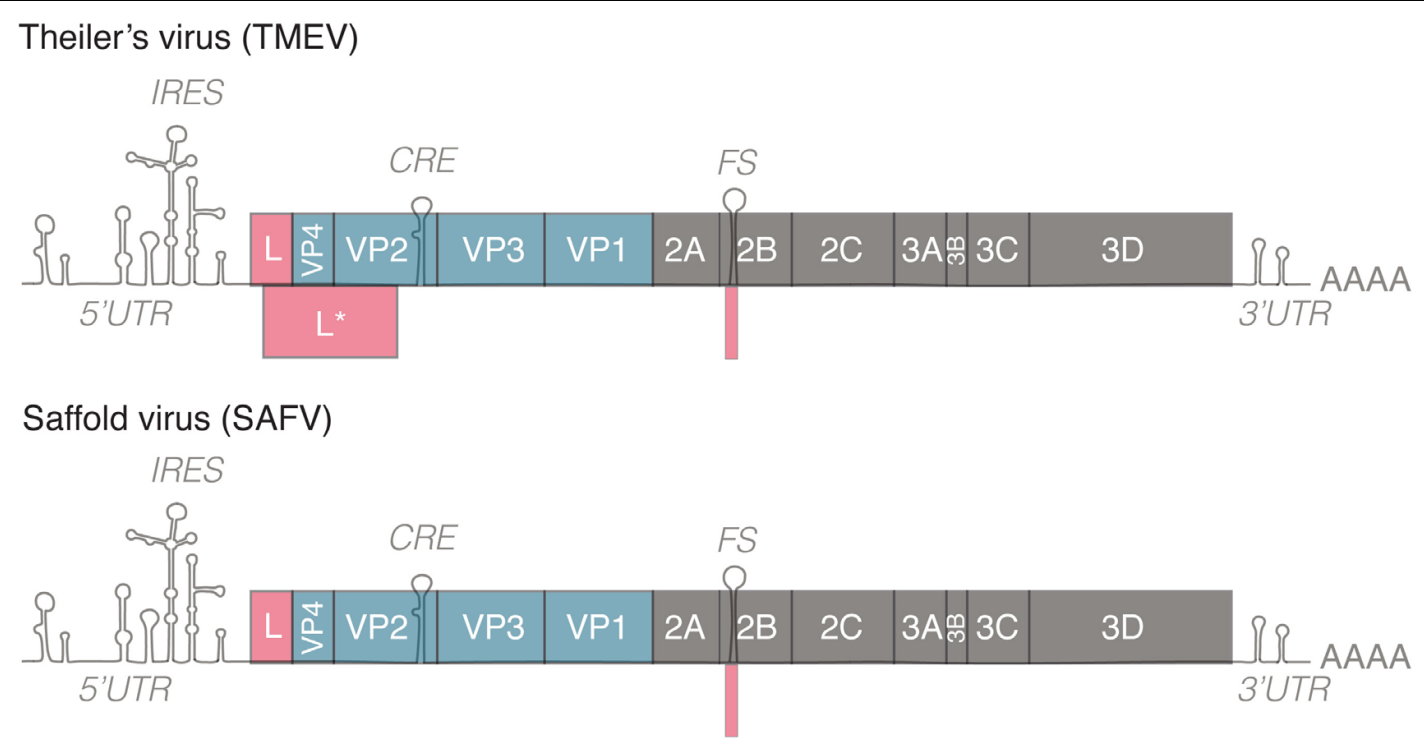

Encephalomyocarditis virus (EMCV)

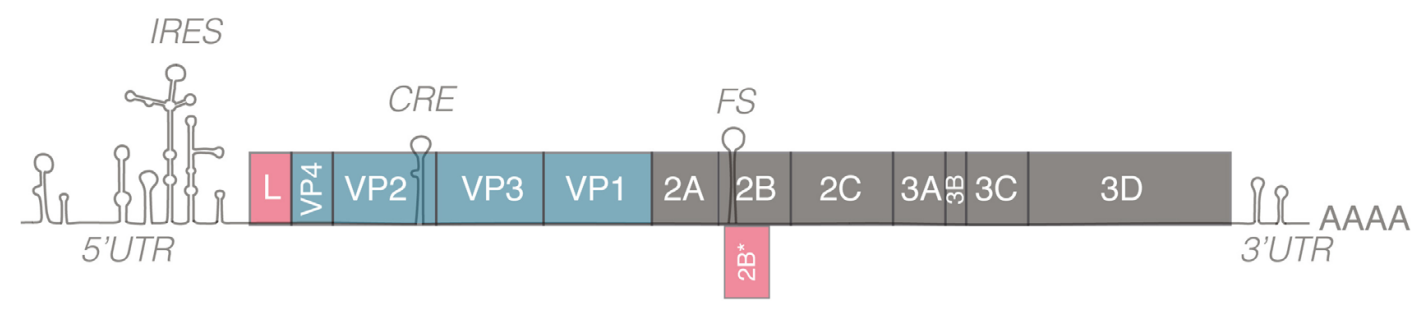

FIGURE 1 | Genomes of representative members of the genus Cardiovirus. All members of the genus Cardiovirus encode a related leader ( $L$ ) protein formed by the $\mathrm{N}$-terminal part of the polyprotein. Theiler's murine encephalomyelitis virus (TMEV) expresses an additional $18 \mathrm{kD}$ protein called $\mathrm{L}^{*}$ from an alternative ORF. TMEV and Saffold virus (SAFV) form the Theilovirus species. These viruses possess a frameshifting site in $2 \mathrm{~B}$ but the $2 \mathrm{~B}^{*} \mathrm{ORF}$ is only $14-15$ codons in length. EMCV encodes a 128-129 residue-long 2B* protein. IRES, internal ribosome entry site; CRE, cis-replication element; FS, frameshifting site. 5'/3'UTR, 5'/3'untranslated region.

In this review, we focus on the ways in which cardioviruses trigger the innate immune response and the efficient mechanisms that they have evolved to suppress these signaling pathways. We consider which cell types may be most important for production of interferon (IFN) in vivo, and also describe how cardioviruses disrupt the functions of interferon effectors.

\section{INDUCTION OF INTERFERON}

Double-stranded RNA (dsRNA) is a necessary product of picornavirus replication, as positive-stranded genome is copied to produce a negative-stranded, full-length template, which is in turn used to produce additional genomes. dsRNA is recognized by several sensor proteins within the cell and triggers a signal transduction pathway that results in transcription of the type I IFN (IFN- $\alpha / \beta)$ genes, as well as IFN- $\lambda$. In the endosome, dsRNA is detected by Toll-like receptor 3 (TLR3), which signals through the adaptor protein TRIF to activate IFN regulatory factor 3 (IRF-3) and nuclear factor kappa B (NF- $\mathrm{B}$ ) (Yamamoto et al., 2003). Cytoplasmic dsRNA is detected by the RIG-I-like receptor (RLR) family of proteins, which includes RIG-I (retinoic acid-induced gene I) and MDA5 (melanoma differentiation-associated gene 5). Upon recognition of dsRNA, these proteins undergo a conformational change that exposes $\mathrm{N}$-terminal caspase activation and recruitment domains (CARDs). The RLRs are then capable of stimulating the mitochondrial antiviral signaling (MAVS) protein, also known as IPS-1, Cardif, and VISA, which in turn activates Tank-binding kinase-1 (TBK1), inducible I-кB kinase (IKK- $\varepsilon$ ) and IRF-3, which then translocates to the nucleus to facilitate transcription of IFN genes (reviewed in Gebhardt et al., 2017).

Although RIG-I and MDA5 both detect dsRNA within the cytosol, their functions are non-redundant. RIG-I recognizes relatively short dsRNA species $(<1 \mathrm{~kb})$ with $5^{\prime} \mathrm{ppp}$ or $5^{\prime} \mathrm{pp}$, which are produced in certain virus infections (Hornung et al., 2006; Pichlmair et al., 2006). In contrast, MDA5 recognizes long dsRNA, which is present during picornavirus replication (Kato et al., 2008; Pichlmair et al., 2009). Thus, while RIG-I is activated during infection with flaviviruses, paramyxoviruses, influenza, and others, MDA5 is responsible for detection of picornaviruses (Gitlin et al., 2006; Kato et al., 2006; Pichlmair et al., 2009; Wang et al., 2010; Feng et al., 2012). The importance of MDA5 for control of cardioviruses was demonstrated in MDA5-deficient mice, which failed to control EMCV infection 
and did not efficiently produce IFN (Gitlin et al., 2006; Kato et al., 2006).

In addition to RIG-like helicases described above, which activate the MAVS pathway, another IFN-inducible RNA helicase, Moloney leukemia virus 10 homolog (MOV10) was reported to enhance IFN induction (Cuevas et al., 2016). MOV10 expression in HEK293 cells restricted EMCV replication. Interestingly, MOV10 acts through IRF-3 activation, in a RLR and MAVS-independent way and signals require IKK- $\varepsilon$ but not TBK1. Such MAVS-independent pathways are likely not critical for global IFN production in EMCV infected mice, given the major impact of MDA5 or MAVS deficiency in mice, but they may be important in specific cell types or in conditions where the other pathways may be less potent.

\section{ACTIVATION OF MDA5 BY CARDIOVIRUSES}

Laboratory of genetics and physiology 2 (LGP2), also known as Dhx58, is also a member of the RLR family but lacks a CARD domain (Yoneyama et al., 2005). Given its structural similarity and lack of a CARD domain, LGP2 was initially thought to negatively regulate dsRNA recognition by RIG-I, as its overexpression limited IFN induction by Sendai virus and Newcastle disease virus (Rothenfusser et al., 2005). However, although the negative effect of LGP2 on RIG-I remained controversial, later studies have established that LGP2 acts as a co-activator of MDA5. Mice deficient for LGP2 were impaired in responding to RNA ligands for MDA5 or to EMCV infection (Venkataraman et al., 2007; Satoh et al., 2010). LGP2 was also shown to increase the rate of MDA5 interaction with RNA and downstream signaling by facilitating the formation of numerous, shorter MDA5 filaments (Bruns et al., 2014). Thus, it appears that LGP2 can act as both a positive and negative regulator of RLR signaling, with the outcome likely dependent on the concentration of LGP2 (Bruns and Horvath, 2015). However, recombinant MDA5 was directly activated as measured by an ATP hydrolysis assay by the replicative form of dsRNA coxsackievirus B3, showing that LGP2 is not essential for activation of MDA5 in vitro by dsRNA (Feng et al., 2012).

Both LGP2 and MDA5 are important for detecting cardiovirus replication. MEFs deficient for either protein produce lower amounts of IFN- $\beta$ when infected with EMCV (Deddouche et al., 2014). Intriguingly, LGP2 may enhance activation of MDA5 during EMCV infection by binding to RNA complementary to the Leader $(\mathrm{L})$ gene and forming a complex with MDA5. This RNA sequence from $\mathrm{L}$ was also shown to be a potent activator of MDA5 in the absence of virus infection (Deddouche et al., 2014).

Although dsRNA can bind and activate recombinant MDA5 in the absence of other proteins, it is likely that additional partners are required for efficient activation of MDA5 in vivo. For example, MDA5 is phosphorylated in resting cells, and requires dephosporylation by PP1 $\alpha / \gamma$ (Wies et al., 2013; Takashima et al., 2015). Additional proteins that participate in recognition of cardiovirus dsRNA have recently been described, including a study showing that TAR RNA binding protein (TRBP) interacts with LGP2 in a yeast two-hybrid screen (Komuro et al., 2016). LGP2 was found to interact with TRBP in co-immunoprecipitation experiments and depletion of TRBP by siRNA reduced interferon production induced by TMEV and EMCV. Moreover, TRBP enhanced IFN induction by TMEV and EMCV when overexpressed. Depletion of TRBP did not affect induction of IFN by Sendai virus, which is recognized by RIG-I. This study establishes that TRBP participates in detection of cardiovirus dsRNA by LGP2/MDA5 but the mechanism and its importance in vivo remain to be elucidated.

As TRBP is a component of the RNAi machinery (Chendrimada et al., 2005; Haase et al., 2005), other molecules involved in RNAi were assessed for their role in dsRNA detection and protein activator of PKR (PACT) was found to also participate in activation of IFN signaling by cardioviruses. When PACT was depleted by siRNA, interferon production was decreased during infection of both TMEV and EMCV. Overexpression of PACT also increased IFN activation when LGP2 was co-expressed with MDA5. Intriguingly, single-stranded TMEV genome enhanced the association of LGP2 and PACT, which suggests that a secondary structure in the TMEV genome might facilitate this interaction (Miyamoto and Komuro, 2017). In a separate report, PACT was shown to be required for induction of IFN by EMCV but not Sendai virus. This study also demonstrated that PACT and MDA5 were recruited to dsRNA (poly(I:C)) but not single stranded RNA, and that PACT expression increased the amount of MDA5 oligomerization (Lui et al., 2017). Both TRBP and PACT have also been reported to bind to double stranded RNA-dependent protein kinase (PKR), and PACT can bind RIG-I (Park et al., 1994; Patel and Sen, 1998; Kok et al., 2011). At the present time, it is not clear if these interactions are important for mediating recognition of cardioviruses.

Yet another partner in detecting dsRNA in cardiovirus infection was recently uncovered. A cDNA screen to identify genes involved in regulating IFN signaling revealed that DHX29 expression increased transcription of an IFN- $\beta$ reporter plasmid in response to high molecular weight (HMW) poly(I:C) (Zhu et al., 2018). Depletion of DHX29 resulted in decreased phosphorylation of TBK1 and IRF-3 in response to HMW poly(I:C) and EMCV as well as decreased production of IFN- $\beta$. The authors also show that DHX29 binds to MDA5 but not MAVS or RIG-I, and binding could only be detected when MDA5 was activated by EMCV or HMW poly(I:C). Mechanistically, this study demonstrated that DHX29 mediated RNA binding of MDA5 by interacting with MDA5 through its $\mathrm{N}$-terminus and RNA through its DEXD and helicase domains, and that DHX29 promotes formation of MDA5 filaments, which are required for activation (Zhu et al., 2018). DHX29 was also independently described to interact with RIG-I (Sugimoto et al., 2014), although it may be of greater importance for activation of MDA5 (Zhu et al., 2018).

Together, these studies show that multiple proteins facilitate recognition of dsRNA by MDA5 during cardiovirus infection (Figure 2). Thus far, these proteins include LGP2, DHX29, PACT and TRBP. Additional helicases are also likely to participate in RLR-dsRNA complex formation but their activities remain to 


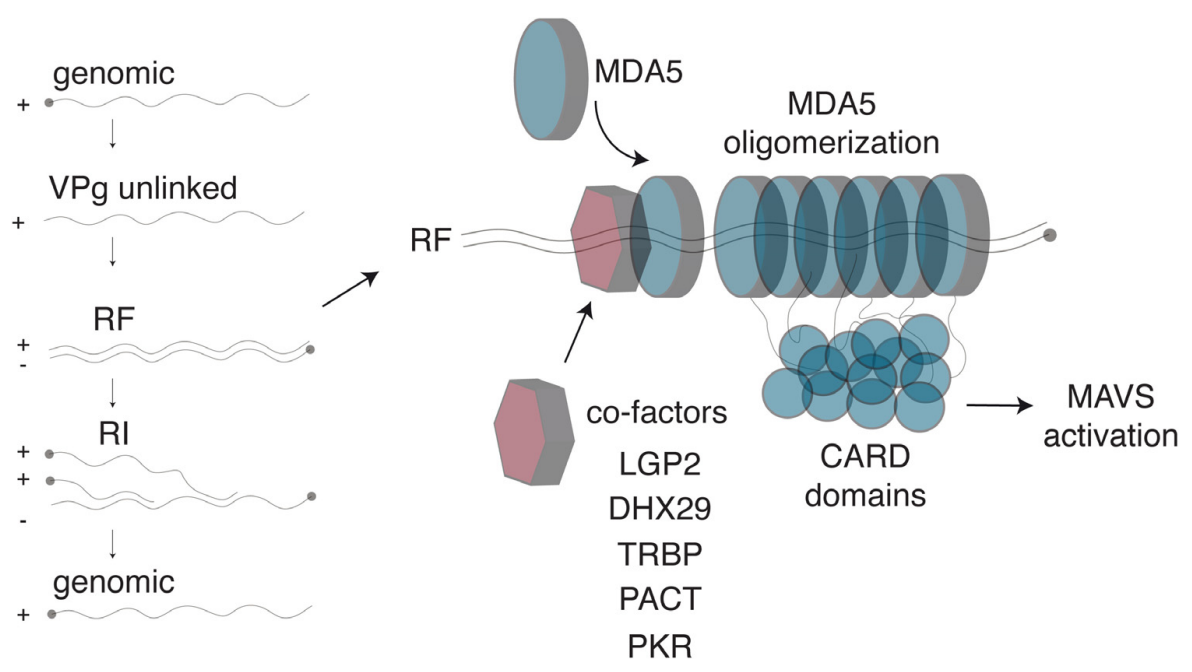

FIGURE 2 | Detection of Cardiovirus dsRNA by MDA5. (Left) After genome delivery into cells, the 3B/VPg protein (closed circle) is cleaved from the 5'end of the RNA. The replicative form (RF) results from synthesis of the negative strand. The newly synthesized negative strand is then used as a template to generate new genomes, via the formation of replicative intermediates (RI). (Right) MDA5 was shown to detect the RF. After dsRNA recognition, MDA5 molecules oligomerize on the dsRNA molecule, exposing their N-terminal CARD domains, which oligomerize and trigger IFN transcription through MAVS activation. Several co-factors, including LGP2 and PKR, were identified that enhance Cardiovirus dsRNA recognition by MDA5, possibly by facilitating initial dsRNA recognition.

be clarified (Oshiumi et al., 2016). Moreover, recent discoveries have identified a novel role for PKR in recognition of dsRNA and activation of MDA5, which will be discussed below. As the number of proteins mediating MDA5 activation grows, so does the number of questions about how this pathway functions. For example, what role does each of the proteins play and how do they work together mechanistically to activate MDA5? Do they play non-redundant roles, or do they function in the same way but in different cell types? Resolving these questions will allow for deeper understanding of the first line of immune defense against RNA viruses.

\section{THE ROLE OF PKR IN ANTIVIRAL RESPONSES TO CARDIOVIRUSES}

Upon recognition of dsRNA, PKR controls virus infection by phosphorylating eukaryotic initiation factor 2 (eIF2 $\alpha$ ), which inhibits translation (Farrell et al., 1977). In this way, an infected cell can suppress production of viral proteins. Phosphorylation of eIF $2 \alpha$ also leads to stress granule formation and induces autophagy, and both pathways are commonly observed during virus infection (Paul and Munz, 2016; Poblete-Duran et al., 2016). Not surprisingly, many viruses have evolved strategies to inhibit the activation or function of PKR (reviewed in Garcia et al., 2007), as evidenced by the fact that PKR-deficiency did not modify the survival time of EMCV infected mice (Yang et al., 1995).

In addition to its role in inhibiting translation, recent evidence has emerged to show that PKR participates in production of IFN. For example, PKR appears to be important for nuclear translocation of IRF-3 following MDA5 activation (Pham et al., 2016). PKR was found to bind to MDA5 and this interaction was not disrupted by nuclease treatment, indicating that binding does not depend on the presence of RNA. In PKR-deficient cells, EMCV infection failed to induce IRF-3 translocation to the nucleus. Moreover, a constitutively active mutant of PKR induced IFN through MAVS. The effect of PKR on induction of IFN required its catalytic activity but did not depend on phosphorylation of eIF $2 \alpha$ (Pham et al., 2016). In a separate report, PKR was shown to be important for normal processing of IFN- $\beta$ mRNA, suggesting that PKR may function at multiple points in the IFN pathway (Schulz et al., 2010). Additionally, activation of PKR by HMW poly(I:C) was shown to be inhibited in cells depleted of MDA5 and MAVS, suggesting that MAVS influences activation of PKR. Moreover, MAVS and PKR were found to interact in co-IP experiments, and the interaction depended on the CARD domain in MAVS and the dsRNA binding domain of PKR (Zhang et al., 2014). Together, these studies clearly indicate a role for PKR in MDA5-dependent IFN induction, although several mechanisms may be involved, which require clarification.

The role of PKR in IFN production after cardiovirus infection remains to be resolved. In one study that examined Mengo virus infection, knockdown of PKR led to decreased induction of IFN- $\beta$ in Hela cells, suggesting that PKR may play a role in the MDA5 pathway during cardiovirus infection (Langereis et al., 2013). This observation fits with the model proposed by Onomoto et al. (2012), which was based on Influenza virus infection and suggests that PKR triggers the formation of "antiviral stress granules" that serve as a recruitment platform for dsRNA and RIG-like helicases, thereby enhancing IFN production. PKR is, however, not essential for IFN production in cardiovirus-infected cells because Mengo virus possessing a deletion in the zinc-finger of L, which abrogates its functions as an interferon antagonist, was found to induce interferon in the cells lacking PKR and RNase L (Feng et al., 2012). Cardioviruses may also inhibit PKR through activity of the L protein, as stress granule formation was 
prevented by the L protein of Mengo, TMEV, and SAFV-2 during virus infection (Borghese and Michiels, 2011). However, direct inhibition of PKR by L remains to be demonstrated.

\section{DETECTION OF EXTRACELLULAR dsRNA}

During infection, viral dsRNA can also be released into the extracellular milieu, either non-specifically during lysis of infected cells or possibly intentionally by exocytosis to trigger innate immunity by uninfected cells. dsRNA can then be endocytosed by neighboring cells and infiltrating immune cells and lead to IFN production. TLR3 recognizes dsRNA in endosomes and signals through TRIF to activate IRF-3 and NF- $\kappa$ B. The importance of TLR3 in context of cardiovirus infection may depend on the model of infection. For example, mice deficient for MyD88 or TLR3 were not significantly more susceptible than wild-type mice to EMCV infection (Kato et al., 2006). In a separate report, however, TLR3-deficient mice had higher viral loads in the liver and heart and were more susceptible to infection (Hardarson et al., 2007). Also, a study that evaluated the role of TLR3 in controlling a strain of EMCV with tropism for $\beta$ cells of the pancreas found that TLR3 protected mice from a fatal infection and that TLR3-deficent mice produced less IFN$\beta$ early in infection (15 and $18 \mathrm{~h}$ post-infection). However, this deficiency was transient and mice lacking TLR3 produced levels of IFN- $\beta$ equivalent to wild-type animals at $24 \mathrm{~h}$ post-infection. In the same experiments, the authors demonstrated that mice lacking MDA5 succumbed to the infection more rapidly than TLR3-deficient mice and produced less IFN- $\beta$ at $24 \mathrm{~h}$ postinfection (McCartney et al., 2011). Finally, a recent report using intracerebral inoculation of the GDVII strain of TMEV evaluated the importance of these molecules for control of virus replication and induction of IFN. Trif-/-, MyD88-/-, and mice lacking both Trif and MyD88 showed wild-type levels of IFN induction, while MAVS-deficient animals were slightly but significantly impaired. When Trif, MyD88 and MAVS were all depleted, however, mice were unable to induce IFN. Only mice lacking MyD88 and Trif, or mice lacking MyD88, Trif and MAVS showed increased titers of GDVII in the brain (Pfefferkorn et al., 2016). Thus, both TLR3 and RLRs contribute to controlling virus replication in vivo, although the relative importance of these pathways may depend on the virus and route of inoculation.

Surprisingly, MDA5 is also responsible for the vast majority of IFN produced from extracellular dsRNA in vivo. Mice deficient for MDA5 produced substantially less IFN when administered polyI:C, whereas TLR3-deficient mice responded like wild-type (Gitlin et al., 2006). These results raise the question of how dsRNA taken up through endocytosis could gain access to the cytoplasm. The mechanism by which dsRNA could be internalized and then access the cytoplasmic RLRs has been unresolved until a recent discovery identified SIDT2, the mammalian ortholog of the SID-1 dsRNA transporter in Caenorhabditis elegans, as a transporter of dsRNA from the endosome to the cytoplasm. SIDT2 was shown to be important for mediating detection of dsRNA in the context of EMCV infection in vivo. Mice that were deficient for SIDT2 failed to control replication, produced less IFN- $\beta$, and succumbed to infection (Nguyen et al., 2017). These data suggest that a crucial pathway for innate signaling in EMCV infection is release of viral RNA into the extracellular milieu, endocytosis, and subsequent transfer of viral RNA to the cytoplasm to access MDA5.

\section{INHIBITION OF INTERFERON PRODUCTION BY CARDIOVIRUSES}

Two proteins encoded by cardioviruses were shown to counteract IFN production in infected cells: protease 3C, which is responsible for the processing of the virus-encoded polyprotein, and the leader protein (L), which corresponds to the $\mathrm{N}$-terminal peptide of the polyprotein.

$3 \mathrm{C}$ is a cysteine proteinase with a trypsin-like serine protease fold, responsible for most cleavages occuring during the maturation of the viral polyprotein (Pelham, 1978). Like 3C proteases of other picornaviruses that were shown to target critical factors involved in IFN induction such as RIG-I (Barral et al., 2009), EMCV 3C was reported to cleave TRAF family member-associated NF-kB activator (TANK) in infected cells, thus disrupting the complex involving TBK1, IKKe and IRF3 and limiting type I IFN production (Huang et al., 2017). Likewise, EMCV 3C was shown to target MOV10, an RNA helicase that acts in a MAVS-independent way, as a possible innate immune evasion mechanism (Cuevas et al., 2016; Figure 3).

$\mathrm{L}$ is a small, multifunctional protein of 67-76 amino acids expressed by all cardioviruses (Figure 1). L contains an $\mathrm{N}$-terminal zinc finger motif (Cys-His-Cys-Cys), an acidic domain, a serine/threonine rich domain, and a C-terminal Theilo domain, which is present in SAFV and TMEV but absent in EMCV. L was shown to be dispensable for replication of TMEV in cell culture but its loss inhibits spread in cells that have a functional interferon response, like L929 cells, and also impairs the viral persistence in vivo (van Pesch et al., 2001). L deletions in

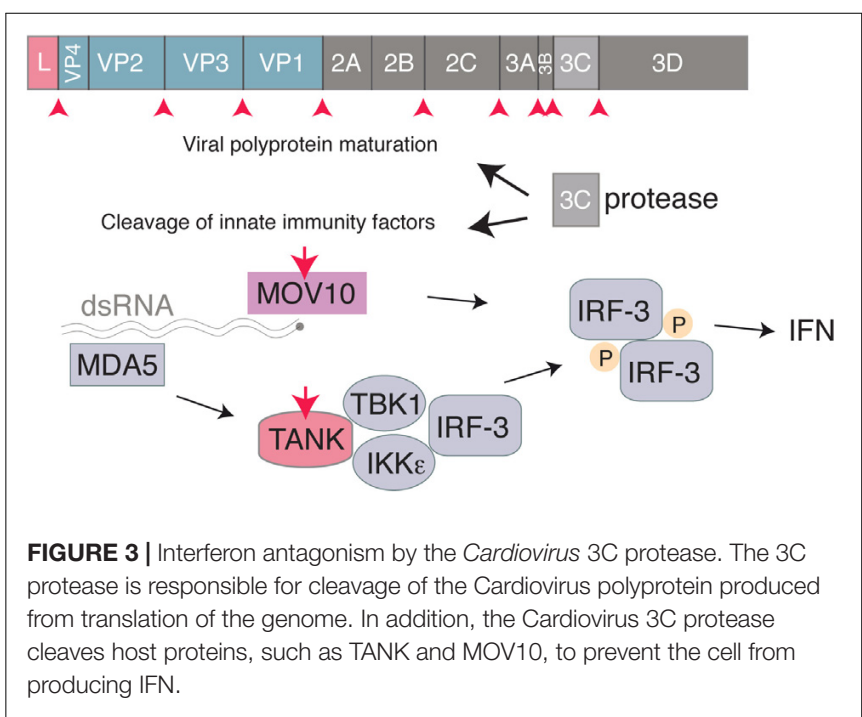


EMCV prevent the virus from shutting off host protein synthesis and enable interferon production (Zoll et al., 1996, 2002). Mengo virus containing a mutation in the zinc finger of $\mathrm{L}$ failed to inhibit IFN synthesis and its replication was inhibited during low MOI infections in vitro. In mice lacking the IFN $\alpha / \beta$ receptor, the mutant virus behaved as wild-type, but in wild-type mice, replication of the $\mathrm{L}$ mutant virus was impaired and it failed to cause disease, demonstrating that activity of $\mathrm{L}$ is important for pathogenesis in vivo (Hato et al., 2007). Mutations in the zinc finger domain or the Theilo domain of TMEV or SAFV L inhibit its ability to antagonize interferon signaling (Ricour et al., 2009).

A critical step in production of IFN following detection of viral replication by MDA5 and other molecules is nuclear translocation of IRF-3 and NF- $\mathrm{kB}$. These proteins enable transcription of the IFN genes to produce mRNA, which must then be exported from the nucleus for translation. Since picornaviruses do not replicate within the nucleus, many viruses within this family disrupt nucleocytoplasmic trafficking, which results in inhibition of IFN production and translocation of nuclear proteins to the cytosol to benefit viral replication (reviewed in Yarbrough et al., 2014; Flather and Semler, 2015). The mechanism of how $\mathrm{L}$ interferes with IFN production may be due to its abilities to disrupt nucleocytoplasmic trafficking, activation of IRF-3, and assembly of stress granules in infected cells (Figure 4). Each of these activities will be explored below.

The L protein of cardioviruses perturbs the function of the nuclear pore complex (NPC) (Porter et al., 2006). In mammals, the NPC consists of approximately 30 different proteins, called nucleoporins (Nups) and enables transit across the nuclear membrane (Gorlich and Kutay, 1999; Wente and Rout, 2010). While small molecules and ions are able to diffuse through the NPC, molecules larger than approximately $20-40 \mathrm{kDa}$ require active transport, which is regulated by transport receptors called karyopherins (Yarbrough et al., 2014). Transport into the nucleus requires a short amino acid motif, called a nuclear localization sequence (NLS) that can interact with either the $\alpha$ or $\beta$ subtypes of karyopherins, depending on the sequence of the protein's NLS. Binding and dissociation of NLS-containing proteins by karyopherins is also regulated by small GTPase Ran. In the cytosol, Ran is bound to GDP and can bind cargo proteins. Once in the nucleus, however, Ran is converted to the GTP bound form by the Ran guanine nucleotide exchange factor (RanGEF) and dissociates from cargo. Export then requires a nuclear export sequence (NES) that binds to karyopherins bound to RanGTP, and dissociation of this complex occurs in the cytoplasm when a Ran GTPase-activating protein (RanGAP) hydrolyzes GTP to GDP. In this way, the RanGDP/GTP gradient regulates directional transport into and out of the nucleus.

Localization of $\mathrm{L}$ to the nucleus depends on expression of 2A, which contains a NLS in its C-terminus (Groppo et al., 2011). Upon nuclear localization, $L$ interacts with Ran with high affinity and $2 \mathrm{~A}$ is displaced as the binding sites for $2 \mathrm{~A}$ and Ran partially overlap (Petty et al., 2014). L from EMCV, TMEV, and SAFV induce hyper-phosphorylation of Nups including
Nup62 and Nup98 (Ricour et al., 2009; Ciomperlik et al., 2015), likely by recruiting and activating a kinase, which may be facilitated by L binding of exportins Crm1 and CAS (Ciomperlik et al., 2016). Chemical inhibition of ERK and p38 was able to block L-mediated hyper-phosphorylation of Nups (Porter et al., 2010). Additionally, L of EMCV is phosphorylated by casein kinase 2 (CK2) and this phosphorylation is required for Nup phosphorylation, although CK2 did not phosphorylate L of SAFV or TMEV (Basta et al., 2014). It is possible, although it remains to be shown, that these kinases also play a role in inhibition of nucleocytoplasmic trafficking by L of TMEV and SAFV.

In addition to its role in disrupting nucleocytoplasmic trafficking, TMEV and Mengo $\mathrm{L}$ prevent production of type I IFN in infected cells by interfering with IRF-3 dimerization and TMEV $\mathrm{L}$ also prevents export of mRNA from the nucleus (Delhaye et al., 2004; Ricour et al., 2009). For both TMEV and Mengo virus, dimerization of IRF-3 was impaired despite the protein having been phosphorylated. Inactivation of IRF-3 occurs despite reports that it accumulates in the nucleus of infected cells (Delhaye et al., 2004). These data suggest that dsRNA is detected in cardiovirus infected cells leading to activation of MAVS and downstream kinases, but that IRF-3 is unable to induce IFN transcription.

Stress granules can form in cells during virus infection and often result from inhibition of translation following phosphorylation of eIF2 $\alpha$ by PKR (White and Lloyd, 2012). The L protein of Mengo, TMEV, and SAFV-2 inhibits stress granule formation during infection and ectopic expression of $\mathrm{L}$ was able to prevent thapsigargin- and arsenite-induced stress granules (Borghese and Michiels, 2011). Stress granules formed during infection with viruses containing deletions in the zinc-finger domain or a mutation in the Theilo domain of $\mathrm{L}$, indicating that these motifs are also important for inhibition of stress granules (Borghese and Michiels, 2011).

While L inhibits nucleocytoplasmic trafficking, stress granule formation, and possibly PKR activation, it has not been possible to uncouple these events using $\mathrm{L}$ mutants. When one function of $\mathrm{L}$ is disrupted, all functions are simultaneously impaired. Therefore, it remains possible that $L$ inhibits IFN production by blocking PKR activation, by interfering with IRF-3 dimerization or nucleocytoplasmic trafficking, or through a combination of these mechanisms (Figure 4).

The importance of these antiviral pathways in controlling infection is underscored by the variety of mechanisms that viruses have evolved to prevent their activity. For example, the $\mathrm{L}$ protein of foot-and-mouth disease virus (FMDV), a picornavirus in the genus Aphthovirus, has proteolytic activity whereas the L protein of cardioviruses does not. Despite the major differences in these proteins, they all still function

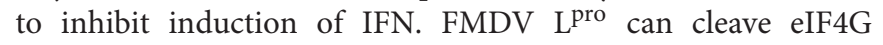
(Devaney et al., 1988; Kirchweger et al., 1994; Guarne et al., 1998) and therefore reduce translation of cellular mRNAs, and can also perturb IFN transcription by cleaving NF- $\kappa B$ (de Los Santos et al., 2006, 2007, 2009). However, in the 


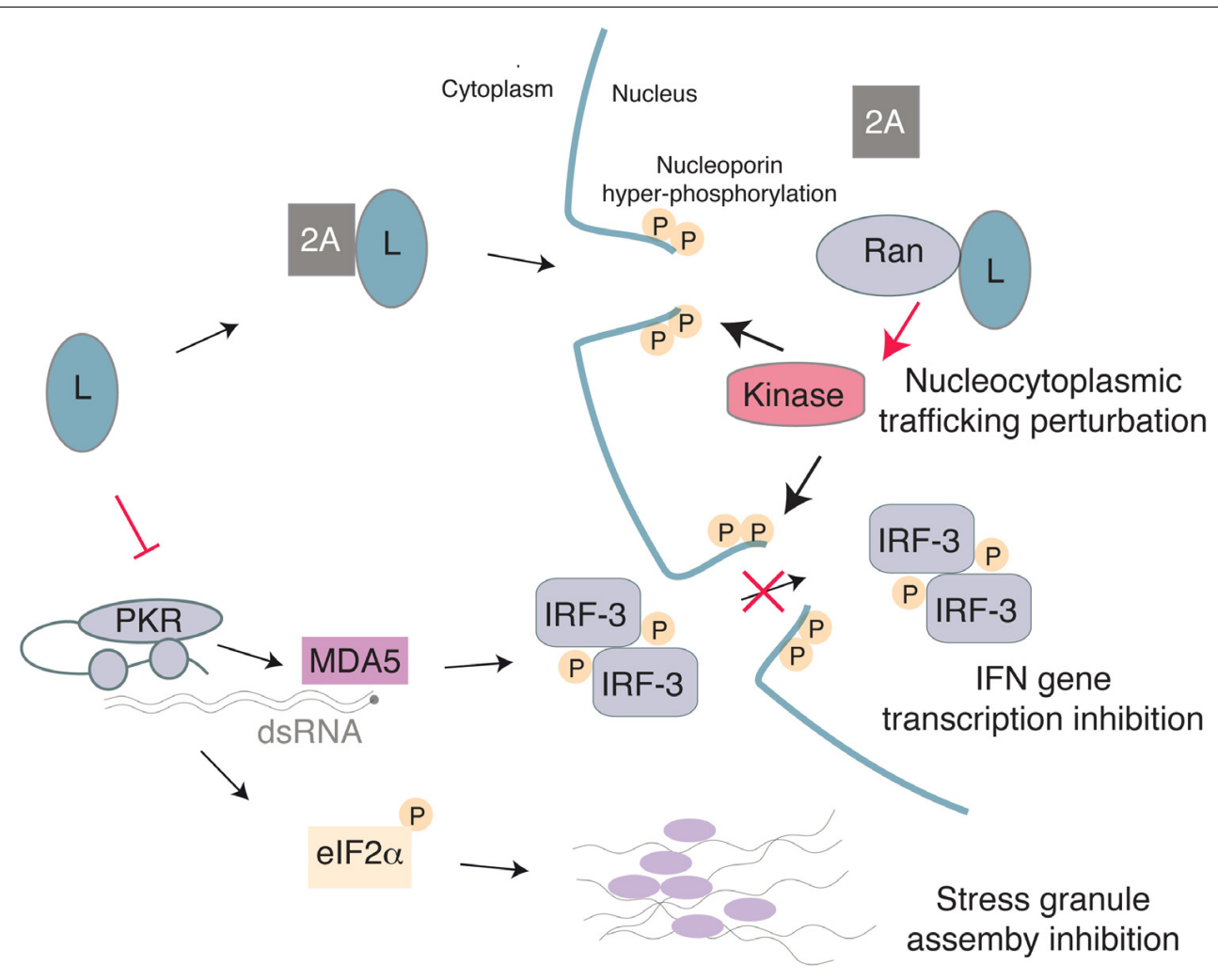

FIGURE 4 | Model for the multiple activities of the Cardiovirus $L$ protein. $L$ binds 2A with low-affinity and the complex may enter the nucleus due to a NLS in $2 A$. Once in the nucleus, L interacts with high affinity with Ran GTPase, thus displacing $2 A$. The L-Ran complex would activate a kinase and trigger nucleoporin hyper-phosphorylation, thereby leading to nuclear pore complex dismantling and to nucleocytoplasmic trafficking perturbation. On the other hand, L may inhibit PKR, thus preventing translation arrest through elF2 $\alpha$ phosphorylation and therefore block assembly of stress granules. Inhibition of IFN gene transcription by $L$ may result from IRF-3 trafficking perturbation and/or from the absence of PKR-enhanced dsRNA detection by MDA5.

context of a chimeric Mengo virus infection, FMDV L was less effective at inhibiting IFN induction in vitro and in vivo (Hato et al., 2010). Similar convergent evolution is apparent when considering the $2 \mathrm{~A}$ protein of picornaviruses. Whereas 2A functions as a protease for most picornaviruses and cleaves mediators of type I interferon signaling, this activity is not present in cardioviruses. Nevertheless, L still targets some of these same molecules for inactivation (Agol and Gmyl, 2010). Additionally, both 2A of enteroviruses and L of cardioviruses inhibit stress granule assembly (Yang et al., 2018).

The functions of L appear to be sufficiently important to the virus so that it maintains high levels of $\mathrm{L}$ expression throughout infection. EMCV and TMEV undergo a frameshift during translation later in infection by $2 \mathrm{~A}$ binding to a stem-loop structure in the genome (Napthine et al., 2017). This frameshift decreases expression of non-structural proteins 2BC-3ABCD by 74-82\% (Finch et al., 2015). A follow up study using metabolic labeling estimated the frameshifting to be $46-76 \%$ efficient (Ling and Firth, 2017). This mechanism may allow for cardioviruses, and perhaps other picornaviruses, to increase the translation of structural proteins later in infection. Due to its position in the genome, however, L expression would remain high throughout infection despite it not having a structural role for virus assembly.
Thus, it may be important for cardioviruses to express sufficient levels of $\mathrm{L}$ to counteract the immune response throughout the replication cycle.

\section{WHAT CELLS ARE MOST IMPORTANT FOR IFN PRODUCTION DURING CARDIOVIRUS INFECTION?}

With effective ways to inhibit the production of interferon during infection, control of cardioviruses likely depends on nearby uninfected cells to produce interferon. Intriguingly, these pathways seem to also depend on MDA5, although TLR3 may also be important in certain cell types such as plasmacytoid dendritic cells (Hornung et al., 2006). As discussed, recent data suggest a model where viral dsRNA is released, endocytosed, and then the RNA is translocated to the cytosol where it is detected by MDA5.

In the CNS, astrocytes appear to be the primary producers of IFN- $\beta$ for several neurotropic viruses that preferentially infect neurons, such as TMEV and La Crosse virus (Kallfass et al., 2012; Pfefferkorn et al., 2016). Using transgenic mice that expressed firefly luciferase under the control of the IFN- $\beta$ promoter restricted to different cell types, the authors were able 
to determine that $73 \%$ of IFN- $\beta$ production during a neurotropic TMEV infection was from astrocytes, whereas only $1 \%$ was from neurons, which are the primary target of infection. In mice lacking MAVS, IFN- $\beta$ production was slightly but significantly reduced, suggesting that the RLR pathway is active during infection but may not be the only pathway activated by TMEV in astrocytes. Intriguingly, mice deficient for MyD88 and Trif did not show a significant decrease in IFN- $\beta$ induction, although induction of IFN- $\beta$ was completely abrogated in mice deficient for MAVS, MyD88 and Trif. Therefore, it appears that both RLR and TLR signaling are important for IFN- $\beta$ production after TMEV infection of the CNS.

Astrocytes were also shown to be primary producers of IFN during infection with rabies virus and vesicular stomatitis virus. In the case of rabies virus, astrocytes are stimulated to produce IFN by an abortive infection. That the virus is unable to replicate fully may prevent expression of viral interferon antagonists and allow for robust production of IFN. How viral replication is prevented in these cells will be important to uncover and may lead to novel insights about viral control in vivo. It is likely that abortive infection of astrocytes occurs during infection by TMEV. However, this remains to be demonstrated and viral RNA may well be encountered by other means.

MDA5 is critical for induction of IFN against cardioviruses in the periphery as well. Ex vivo, cells such as macrophages, conventional dendritic cells and fibroblasts depend on MAVS for production of IFN in response to dsRNA (Sun et al., 2006).
Similarly, MDA5 was shown to be essential in these cells for type I IFN production after EMCV infection, in contrast to pDCs which induce IFN production in a TLR-dependent fashion (Gitlin et al., 2006; Kato et al., 2006). After EMCV infection of mice, some IFN is produced through TLRs, likely by pDCs, but most IFN was produced by MDA5 activation (Gitlin et al., 2006; Kato et al., 2006). Levels of IFN-I were strongly decreased in the serum of MDA5-deficient mice infected by EMCV. Whereas MDA5 expression strongly influenced survival in response to infection, the effect of MyD88 depletion had a modest effect and loss of Trif or RIG-I did not affect survival (Kato et al., 2006). Thus, MDA5 is essential for controlling EMCV infection in the periphery.

\section{CARDIOVIRUS INHIBITION OF IFN EFFECTORS}

Interferon secreted by infected cells binds to its receptor on surrounding cells, activating a signaling cascade that leads to expression of hundreds of interferon-stimulated genes (ISGs). Two of these ISGs, PKR and oligoadenylate synthetases (OAS) are part of the best-characterized interferon effector pathways.

As described earlier, PKR is likely antagonized by the $\mathrm{L}$ protein, as L inhibits PKR-induced stress granule assembly. Moreover, a recent study reported increased SUMO3 conjugation

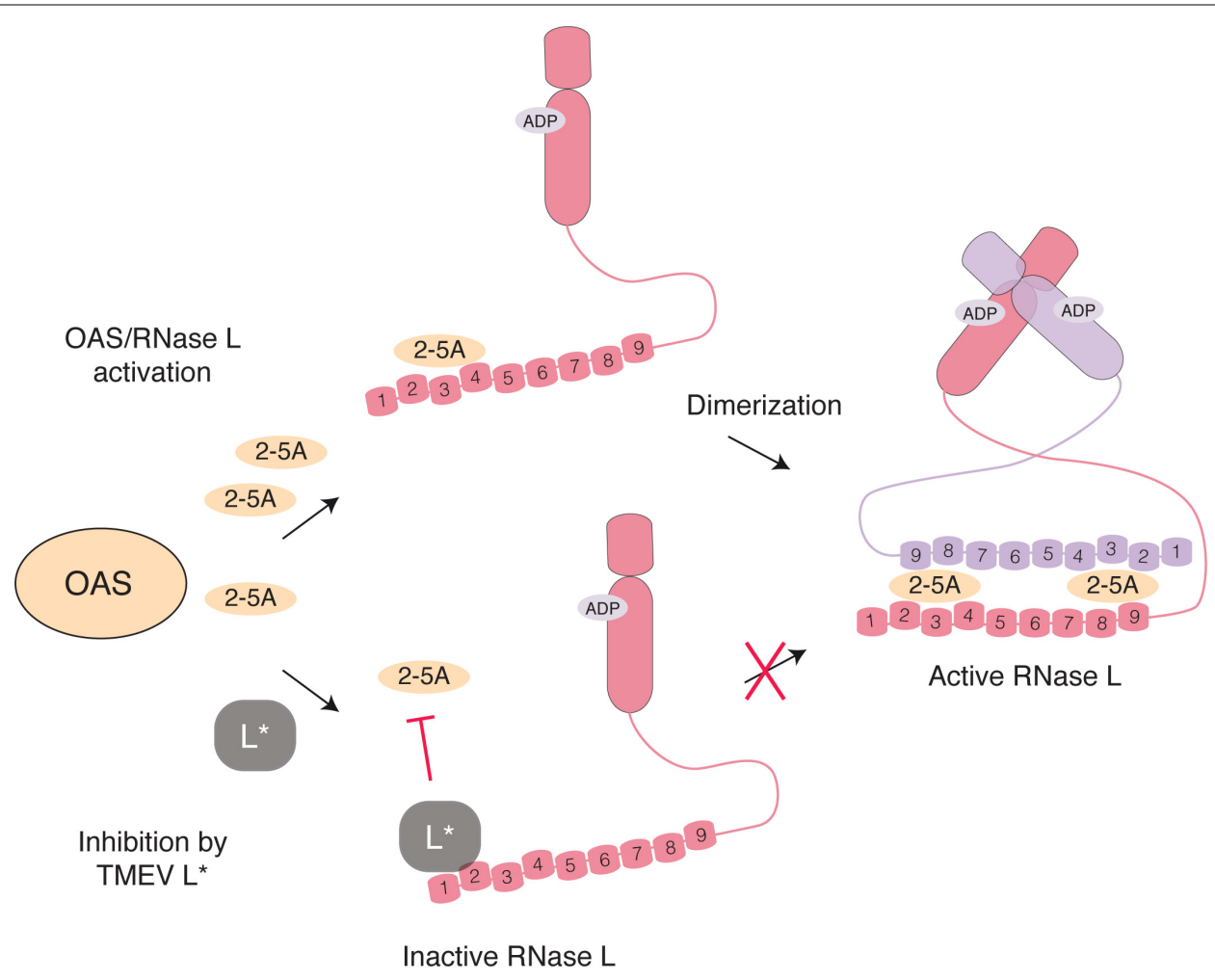

FIGURE 5 | Inhibition of RNase L activation by L* TMEV L* binds RNase L ankyrin repeats 1 and 2 (numbered) through a direct protein-protein interaction, thereby preventing association of $2-5 \mathrm{~A}$ with $\mathrm{RNase} L$ monomers and the consequent dimerization and activation of the enzyme. 
of PKR in EMCV-infected cells, which dampens PKR activation and promotes caspase-dependent PKR degradation (Maarifi et al., 2018).

Oligoadenylate synthetases are enzymes responsible for RNase L activation. Cardioviruses have evolved two strategies to interfere with the OAS-RNase L pathway. In an infected cell, OAS are activated by dsRNA and produce $2^{\prime}-5^{\prime}$ oligoadenylates (2-5A). Binding of two 2-5A molecules to the ankyrin domain of the latent endoribonuclease RNase $L$ triggers its dimerization and activation (Figure 5). Active RNase L then cleaves viral and cellular ssRNA leading to decreased viral replication and ultimately to apoptosis of the cell. Interestingly, RNA fragments generated by RNase L can amplify IFN production in a RIG-I, MDA5 and MAVS-dependent way (Malathi et al., 2007). RNase L targets both viral and cellular mRNA but is also predicted to cleave the genome of ssRNA viruses, as reported for EMCV (Li et al., 1998). In addition to $2^{\prime}$-phosphodiesterases and phosphatases that tightly regulate the system by degrading $2-5 \mathrm{~A}$ within minutes of their synthesis, RNase L activity can be negatively regulated by the RNase L inhibitor (RLI/ABCE) (Bisbal et al., 1995).

RLI/ABCE expression is induced by EMCV and correlates with RNase L inhibition (Martinand et al., 1999). Accordingly, overexpression of RLI/ABCE inhibited the action of IFN against EMCV (Bisbal et al., 1995). RNase L inhibition by EMCV-induced RLI is, however, partial as RNase L antiviral activity against EMCV was demonstrated in vitro using dominant negative RNase L and OAS1 overexpression (Chebath et al., 1987; Zhou et al., 1998) and in vivo, in RNase L-deficient mice, which presented increased EMCV infection and mortality compared to wild-type mice (Zhou et al., 1997).

The $\mathrm{L}^{*}$ protein of TMEV was found to potently inhibit RNase $\mathrm{L}$ through a direct protein-protein interaction (Sorgeloos et al., 2013). Mechanistically, $\mathrm{L}^{*}$ binds to RNase L ankyrin repeats 1 and 2, thereby preventing 2-5A binding to the enzyme and further activation steps (Drappier et al., 2018; Figure 5). In wild-type macrophages, replication of $\mathrm{L}^{*}$-mutant was significantly impaired as compared to that of the wild-type virus (Sorgeloos et al., 2013). In contrast, L*-mutant and wildtype viruses replicated to the same level in RNase L-deficient primary peritoneal macrophages. Moreover, $\mathrm{L}^{*}$ was shown to be active in vivo in the context of MHV chimeric viruses; $\mathrm{L}^{*}$ could substitute for another viral RNase L inhibitor, namely the ns2 phosphodiesterase of MHV, in the liver of infected mice (Drappier et al., 2018). The fact that the virus devotes one of its proteins to RNase L antagonism highlights the importance of this antiviral pathway against TMEV. Interestingly RNase L inhibition by $\mathrm{L}^{*}$ is highly species-specific; $\mathrm{L}^{*}$ of a mouse TMEV strain inhibits mouse RNase L but not its orthologs from other species including rat (Sorgeloos et al., 2013; Drappier et al., 2018). Accordingly, $\mathrm{L}^{*}$ of a rat TMEV strain inhibits rat but not mouse RNase L.

Theiler's murine encephalomyelitis virus is the only cardiovirus expressing $\mathrm{L}^{*}$, and thus the only cardiovirus known to directly inhibit RNase L. This could stem from its tropism for macrophages, which are the main TMEV target during the chronic phase of infection and in which the OAS-RNase L system is particularly active (Zhao et al., 2012). However, macrophages were reported to play important roles in EMCV pathogenesis, including for viral replication and dissemination in piglets (Papaioannou et al., 2003) and as reservoir cells for EMCV persistence in rats (Psalla et al., 2006). Since EMCV is sensitive to RNase L activity, it is possible that another EMCV protein will have developed some RNase L antagonistic activity, which might be identified using the appropriate host-pathogen context. Interactions between SAFVs and RNase L have yet to be described, but it is also likely that these viruses have evolved ways of inhibiting this pathway.

\section{CONCLUSION AND FUTURE PERSPECTIVES}

Given the many ways that picornaviruses inhibit interferon production and signaling in infected cells, it is not surprising that the most important producers of IFN would be uninfected or abortively infected cells. Indeed, cardioviruses efficiently block IFN in infected cells but loss of MDA5 in mice causes them to be more susceptible to virus infection. These data indicate that detection of cytoplasmic dsRNA by MDA5 occurs in cells that are not productively infected (Gitlin et al., 2006) and the recent finding that SIDT2 mediates this process opens many new exciting areas of research (Nguyen et al., 2017). Which molecules might be important for release of viral RNA? Is there a role for exosomes in this process? How might these pathways be stimulated pharmacologically? Preventing release of viral RNA and subsequent detection by uninfected cells may represent selective pressure favoring non-lytic release. Given the exquisite genetic malleability in response to natural selection displayed by viruses, it is likely that viruses will have evolved mechanisms of inhibiting detection of viral RNA by uninfected cells, perhaps by restricting dsRNA release or by secreting proteins that inhibit RNA transport into uninfected cells. It will be exciting to see how discoveries unfold in this area of research.

Several recent studies involving cardioviruses have revealed a more complicated picture regarding initial detection of replicating RNA and induction of IFN. While it is clear that the helicases LGP2, DHX29, PACT and TRBP work in concert with MDA5 for detection of dsRNA, it remains to be determined how these molecules coordinate and interact and whether they function in a cell-type specific manner. It will also be important to resolve the way in which PKR functions to activate IFN signaling. Future studies in this area will likely have broad relevance for innate detection of viruses.

Finally, the mechanisms by which L disrupts nucleocytoplasmic trafficking, stress granule formation, and interferon production clearly require further clarification. Mutational analysis of $\mathrm{L}$ has revealed that these activities are tightly coupled, suggesting that the L interacts with protein(s) that can serve as a common node in each of these pathways. 
As IFN signaling and stress granules are important for a variety of viral pathogens, answers to these questions may provide broadly relevant insight into host-pathogen interactions.

\section{AUTHOR CONTRIBUTIONS}

EF, MD, and TM wrote the manuscript and approved its final version.

\section{REFERENCES}

Agol, V. I., and Gmyl, A. P. (2010). Viral security proteins: counteracting host defences. Nat. Rev. Microbiol. 8, 867-878. doi: 10.1038/nrmicro2452

Barral, P. M., Sarkar, D., Fisher, P. B., and Racaniello, V. R. (2009). RIG-I is cleaved during picornavirus infection. Virology 391, 171-176. doi: 10.1016/j.virol.2009. 06.045

Basta, H. A., Bacot-Davis, V. R., Ciomperlik, J. J., and Palmenberg, A. C. (2014). Encephalomyocarditis virus leader is phosphorylated by CK2 and syk as a requirement for subsequent phosphorylation of cellular nucleoporins. J. Virol. 88, 2219-2226. doi: 10.1128/JVI.03150-13

Bisbal, C., Martinand, C., Silhol, M., Lebleu, B., and Salehzada, T. (1995). Cloning and characterization of a RNAse L inhibitor. A new component of the interferon-regulated 2-5A pathway. J. Biol. Chem. 270, 13308-13317. doi: 10. $1074 /$ jbc. 270.22 .13308

Borghese, F., and Michiels, T. (2011). The leader protein of cardioviruses inhibits stress granule assembly. J. Virol. 85, 9614-9622. doi: 10.1128/JVI.004 80-11

Brahic, M., Bureau, J. F., and Michiels, T. (2005). The genetics of the persistent infection and demyelinating disease caused by Theiler's virus. Annu. Rev. Microbiol. 59, 279-298. doi: 10.1146/annurev.micro.59.030804.121242

Bruns, A. M., and Horvath, C. M. (2015). LGP2 synergy with MDA5 in RLRmediated RNA recognition and antiviral signaling. Cytokine 74, 198-206. doi: 10.1016/j.cyto.2015.02.010

Bruns, A. M., Leser, G. P., Lamb, R. A., and Horvath, C. M. (2014). The innate immune sensor LGP2 activates antiviral signaling by regulating MDA5-RNA interaction and filament assembly. Mol. Cell 55, 771-781. doi: 10.1016/j.molcel. 2014.07.003

Carocci, M., and Bakkali-Kassimi, L. (2012). The encephalomyocarditis virus. Virulence 3, 351-367. doi: 10.4161/viru.20573

Chebath, J., Benech, P., Revel, M., and Vigneron, M. (1987). Constitutive expression of (2'-5') oligo A synthetase confers resistance to picornavirus infection. Nature 330, 587-588. doi: 10.1038/330587a0

Chendrimada, T. P., Gregory, R. I., Kumaraswamy, E., Norman, J., Cooch, N., Nishikura, K., et al. (2005). TRBP recruits the Dicer complex to Ago2 for microRNA processing and gene silencing. Nature 436, 740-744. doi: 10.1038/ nature 03868

Ciomperlik, J. J., Basta, H. A., and Palmenberg, A. C. (2015). Three cardiovirus Leader proteins equivalently inhibit four different nucleocytoplasmic trafficking pathways. Virology 484, 194-202. doi: 10.1016/j.virol.2015.06.004

Ciomperlik, J. J., Basta, H. A., and Palmenberg, A. C. (2016). Cardiovirus Leader proteins bind exportins: implications for virus replication and nucleocytoplasmic trafficking inhibition. Virology 487, 19-26. doi: 10.1016/j. virol.2015.10.001

Cuevas, R. A., Ghosh, A., Wallerath, C., Hornung, V., Coyne, C. B., and Sarkar, S. N. (2016). MOV10 provides antiviral activity against RNA viruses by enhancing RIG-I-MAVS-independent IFN induction. J. Immunol. 196, 3877-3886. doi: 10.4049/jimmunol.1501359

de Los Santos, T., De Avila Botton, S., Weiblen, R., and Grubman, M. J. (2006). The leader proteinase of foot-and-mouth disease virus inhibits the induction of beta interferon mRNA and blocks the host innate immune response. J. Virol. 80, 1906-1914. doi: 10.1128/JVI.80.4.1906-1914.2006

de Los Santos, T., Diaz-San Segundo, F., and Grubman, M. J. (2007). Degradation of nuclear factor kappa B during foot-and-mouth disease virus infection. J. Virol. 81, 12803-12815. doi: 10.1128/JVI.01467-07

\section{FUNDING}

EF was supported by a David Delo Research Grant. MD was supported by Action de Recherches Concertée (ARC). Research in the TM lab was supported by the Belgian Fund for Medical Research (FRSM, PDR \# T.0185.14) and by EOS joint program of Fonds de la Recherche Scientifique - FNRS and Fonds wetenschapelijk onderzoek - Vlaanderen - FWO (EOS ID: 30981113).

de Los Santos, T., Segundo, F. D., Zhu, J., Koster, M., Dias, C. C., and Grubman, M. J. (2009). A conserved domain in the leader proteinase of foot-and-mouth disease virus is required for proper subcellular localization and function. J. Virol. 83, 1800-1810. doi: 10.1128/JVI.02112-08

Deddouche, S., Goubau, D., Rehwinkel, J., Chakravarty, P., Begum, S., Maillard, P. V., et al. (2014). Identification of an LGP2-associated MDA5 agonist in picornavirus-infected cells. eLife 3:e01535. doi: 10.7554/eLife.0 1535

Delhaye, S., Van Pesch, V., and Michiels, T. (2004). The leader protein of Theiler's virus interferes with nucleocytoplasmic trafficking of cellular proteins. J. Virol. 78, 4357-4362. doi: 10.1128/JVI.78.8.4357-4362.2004

Devaney, M. A., Vakharia, V. N., Lloyd, R. E., Ehrenfeld, E., and Grubman, M. J. (1988). Leader protein of foot-and-mouth disease virus is required for cleavage of the p220 component of the cap-binding protein complex. J. Virol. $62,4407-4409$.

Dick, G. W. A., Haddow, A. J., Best, A. M., and Smithburn, K. C. (1948). Mengo encephalomyelitis; a hitherto unknown virus affecting man. Lancet 2, 286-289. doi: 10.1016/S0140-6736(48)90652-7

Drappier, M., Jha, B. K., Stone, S., Elliott, R., Zhang, R., Vertommen, D., et al. (2018). A novel mechanism of RNase $L$ inhibition: Theiler's virus $L^{*}$ protein prevents 2-5A from binding to RNase L. PLoS Pathog. 14:e1006989. doi: 10. 1371/journal.ppat.1006989

Farrell, P. J., Balkow, K., Hunt, T., Jackson, R. J., and Trachsel, H. (1977). Phosphorylation of initiation factor elF-2 and the control of reticulocyte protein synthesis. Cell 11, 187-200. doi: 10.1016/0092-8674(77)90330-0

Feng, Q., Hato, S. V., Langereis, M. A., Zoll, J., Virgen-Slane, R., Peisley, A., et al. (2012). MDA5 detects the double-stranded RNA replicative form in picornavirus-infected cells. Cell Rep. 2, 1187-1196. doi: 10.1016/j.celrep.2012. 10.005

Finch, L. K., Ling, R., Napthine, S., Olspert, A., Michiels, T., Lardinois, C., et al. (2015). Characterization of ribosomal frameshifting in Theiler's murine encephalomyelitis virus. J. Virol. 89, 8580-8589. doi: 10.1128/JVI.01043-15

Flather, D., and Semler, B. L. (2015). Picornaviruses and nuclear functions: targeting a cellular compartment distinct from the replication site of a positivestrand RNA virus. Front. Microbiol. 6:594. doi: 10.3389/fmicb.2015.00594

Garcia, M. A., Meurs, E. F., and Esteban, M. (2007). The dsRNA protein kinase PKR: virus and cell control. Biochimie 89, 799-811. doi: 10.1016/j.biochi.2007. 03.001

Gebhardt, A., Laudenbach, B. T., and Pichlmair, A. (2017). Discrimination of self and non-self ribonucleic acids. J. Interferon Cytokine Res. 37, 184-197. doi: 10.1089/jir.2016.0092

Gitlin, L., Barchet, W., Gilfillan, S., Cella, M., Beutler, B., Flavell, R. A., et al. (2006). Essential role of mda-5 in type I IFN responses to polyriboinosinic:polyribocytidylic acid and encephalomyocarditis picornavirus. Proc. Natl. Acad. Sci. U.S.A. 103, 8459-8464. doi: 10.1073/pnas.0603082103

Gorlich, D., and Kutay, U. (1999). Transport between the cell nucleus and the cytoplasm. Annu. Rev. Cell Dev. Biol. 15, 607-660. doi: 10.1146/annurev.cellbio. 15.1.607

Groppo, R., Brown, B. A., and Palmenberg, A. C. (2011). Mutational analysis of the EMCV 2A protein identifies a nuclear localization signal and an eIF4E binding site. Virology 410, 257-267. doi: 10.1016/j.virol.2010.11.002

Guarne, A., Tormo, J., Kirchweger, R., Pfistermueller, D., Fita, I., and Skern, T. (1998). Structure of the foot-and-mouth disease virus leader protease: a papainlike fold adapted for self-processing and eIF4G recognition. EMBO J. 17, 7469-7479. doi: 10.1093/emboj/17.24.7469 
Haase, A. D., Jaskiewicz, L., Zhang, H., Laine, S., Sack, R., Gatignol, A., et al. (2005). TRBP, a regulator of cellular PKR and HIV-1 virus expression, interacts with Dicer and functions in RNA silencing. EMBO Rep. 6, 961-967. doi: 10.1038/sj. embor.7400509

Hardarson, H. S., Baker, J. S., Yang, Z., Purevjav, E., Huang, C. H., Alexopoulou, L., et al. (2007). Toll-like receptor 3 is an essential component of the innate stress response in virus-induced cardiac injury. Am. J. Physiol. Heart Circ. Physiol. 292, H251-H258. doi: 10.1152/ajpheart.00398.2006

Hato, S. V., Ricour, C., Schulte, B. M., Lanke, K. H., De Bruijni, M., Zoll, J., et al. (2007). The mengovirus leader protein blocks interferon-alpha/beta gene transcription and inhibits activation of interferon regulatory factor 3. Cell. Microbiol. 9, 2921-2930. doi: 10.1111/j.1462-5822.2007.01006.x

Hato, S. V., Sorgeloos, F., Ricour, C., Zoll, J., Melchers, W. J., Michiels, T., et al. (2010). Differential IFN-alpha/beta production suppressing capacities of the leader proteins of mengovirus and foot-and-mouth disease virus. Cell. Microbiol. 12, 310-317. doi: 10.1111/j.1462-5822.2009.01395.x

Hornung, V., Ellegast, J., Kim, S., Brzozka, K., Jung, A., Kato, H., et al. (2006). 5'Triphosphate RNA is the ligand for RIG-I. Science 314, 994-997. doi: 10.1126/ science. 1132505

Huang, L., Xiong, T., Yu, H., Zhang, Q., Zhang, K., Li, C., et al. (2017). Encephalomyocarditis virus $3 \mathrm{C}$ protease attenuates type I interferon production through disrupting the TANK-TBK1-IKKepsilon-IRF3 complex. Biochem. J. 474, 2051-2065. doi: 10.1042/BCJ20161037

Kallfass, C., Ackerman, A., Lienenklaus, S., Weiss, S., Heimrich, B., and Staeheli, P. (2012). Visualizing production of beta interferon by astrocytes and microglia in brain of La Crosse virus-infected mice. J. Virol. 86, 11223-11230. doi: 10.1128/ JVI.01093-12

Kato, H., Takeuchi, O., Mikamo-Satoh, E., Hirai, R., Kawai, T., Matsushita, K., et al. (2008). Length-dependent recognition of double-stranded ribonucleic acids by retinoic acid-inducible gene-I and melanoma differentiation-associated gene 5 . J. Exp. Med. 205, 1601-1610. doi: 10.1084/jem.20080091

Kato, H., Takeuchi, O., Sato, S., Yoneyama, M., Yamamoto, M., Matsui, K., et al. (2006). Differential roles of MDA5 and RIG-I helicases in the recognition of RNA viruses. Nature 441, 101-105. doi: 10.1038/nature04734

Kirchweger, R., Ziegler, E., Lamphear, B. J., Waters, D., Liebig, H. D., Sommergruber, W., et al. (1994). Foot-and-mouth disease virus leader proteinase: purification of the $\mathrm{Lb}$ form and determination of its cleavage site on eIF-4 gamma. J. Virol. 68, 5677-5684.

Kok, K. H., Lui, P. Y., Ng, M. H., Siu, K. L., Au, S. W., and Jin, D. Y. (2011). The double-stranded RNA-binding protein PACT functions as a cellular activator of RIG-I to facilitate innate antiviral response. Cell Host Microbe 9, 299-309. doi: 10.1016/j.chom.2011.03.007

Komuro, A., Homma, Y., Negoro, T., Barber, G. N., and Horvath, C. M. (2016). The TAR-RNA binding protein is required for immunoresponses triggered by Cardiovirus infection. Biochem. Biophys. Res. Commun. 480, 187-193. doi: 10.1016/j.bbrc.2016.10.023

Langereis, M. A., Feng, Q., and Van Kuppeveld, F. J. (2013). MDA5 localizes to stress granules, but this localization is not required for the induction of type I interferon. J. Virol. 87, 6314-6325. doi: 10.1128/JVI.03213-12

Li, X. L., Blackford, J. A., and Hassel, B. A. (1998). RNase L mediates the antiviral effect of interferon through a selective reduction in viral RNA during encephalomyocarditis virus infection. J. Virol. 72, 2752-2759.

Ling, R., and Firth, A. E. (2017). An analysis by metabolic labelling of the encephalomyocarditis virus ribosomal frameshifting efficiency and stimulators. J. Gen. Virol. 98, 2100-2105. doi: 10.1099/jgv.0.000888

Loughran, G., Firth, A. E., and Atkins, J. F. (2011). Ribosomal frameshifting into an overlapping gene in the $2 \mathrm{~B}$-encoding region of the cardiovirus genome. Proc. Natl. Acad. Sci. U.S.A. 108, E1111-E1119. doi: 10.1073/pnas.1102932108

Lui, P. Y., Wong, L. R., Ho, T. H., Au, S. W. N., Chan, C. P., Kok, K. H., et al. (2017). PACT facilitates RNA-induced activation of MDA5 by promoting MDA5 oligomerization. J. Immunol. 199, 1846-1855. doi: 10.4049/jimmunol. 1601493

Maarif, G., El Asmi, F., Maroui, M. A., Dianoux, L., and Chelbi-Alix, M. K. (2018). Differential effects of SUMO1 and SUMO3 on PKR activation and stability. Sci. Rep. 8:1277. doi: 10.1038/s41598-018-19683-6

Malathi, K., Dong, B., Gale, M. Jr., and Silverman, R. H. (2007). Small self-RNA generated by RNase L amplifies antiviral innate immunity. Nature 448, 816-819. doi: $10.1038 /$ nature 06042
Martinand, C., Montavon, C., Salehzada, T., Silhol, M., Lebleu, B., and Bisbal, C. (1999). RNase L inhibitor is induced during human immunodeficiency virus type 1 infection and down regulates the $2-5 \mathrm{~A} / \mathrm{RN}$ ase $\mathrm{L}$ pathway in human $\mathrm{T}$ cells. J. Virol. 73, 290-296.

McCartney, S. A., Vermi, W., Lonardi, S., Rossini, C., Otero, K., Calderon, B., et al. (2011). RNA sensor-induced type I IFN prevents diabetes caused by a beta cell-tropic virus in mice. J. Clin. Invest. 121, 1497-1507. doi: 10.1172/JCI44005

Miyamoto, M., and Komuro, A. (2017). PACT is required for MDA5-mediated immunoresponses triggered by Cardiovirus infection via interaction with LGP2. Biochem. Biophys. Res. Commun. 494, 227-233. doi: 10.1016/j.bbrc.2017. 10.048

Napthine, S., Ling, R., Finch, L. K., Jones, J. D., Bell, S., Brierley, I., et al. (2017). Protein-directed ribosomal frameshifting temporally regulates gene expression. Nat. Commun. 8:15582. doi: 10.1038/ncomms 15582

Nguyen, T. A., Smith, B. R. C., Tate, M. D., Belz, G. T., Barrios, M. H., Elgass, K. D., et al. (2017). SIDT2 transports extracellular dsRNA into the cytoplasm for innate immune recognition. Immunity 47, 498-509.e6. doi: 10.1016/j.immuni. 2017.08.007

Onomoto, K., Jogi, M., Yoo, J. S., Narita, R., Morimoto, S., Takemura, A., et al. (2012). Critical role of an antiviral stress granule containing RIG-I and PKR in viral detection and innate immunity. PLoS One 7:e43031. doi: 10.1371/journal. pone. 0043031

Oshiumi, H., Kouwaki, T., and Seya, T. (2016). Accessory factors of cytoplasmic viral RNA sensors required for antiviral innate immune response. Front. Immunol. 7:200. doi: 10.3389/fimmu.2016.00200

Papaioannou, N., Billinis, C., Psychas, V., Papadopoulos, O., and Vlemmas, I. (2003). Pathogenesis of encephalomyocarditis virus (EMCV) infection in piglets during the viraemia phase: a histopathological, immunohistochemical and virological study. J. Comp. Pathol. 129, 161-168. doi: 10.1016/S0021-9975(03) 00026-4

Park, H., Davies, M. V., Langland, J. O., Chang, H. W., Nam, Y. S., Tartaglia, J., et al. (1994). TAR RNA-binding protein is an inhibitor of the interferon-induced protein kinase PKR. Proc. Natl. Acad. Sci. U.S.A. 91, 4713-4717. doi: 10.1073/ pnas.91.11.4713

Patel, R. C., and Sen, G. C. (1998). PACT, a protein activator of the interferoninduced protein kinase, PKR. EMBO J. 17, 4379-4390. doi: 10.1093/emboj/17. 15.4379

Paul, P., and Munz, C. (2016). Autophagy and mammalian viruses: roles in immune response, viral replication, and beyond. Adv. Virus Res. 95, 149-195. doi: 10. 1016/bs.aivir.2016.02.002

Pelham, H. R. (1978). Translation of encephalomyocarditis virus RNA in vitro yields an active proteolytic processing enzyme. Eur. J. Biochem. 85, 457-462. doi: 10.1111/j.1432-1033.1978.tb12260.x

Petty, R. V., Basta, H. A., Bacot-Davis, V. R., Brown, B. A., and Palmenberg, A. C. (2014). Binding interactions between the encephalomyocarditis virus leader and protein 2A. J. Virol. 88, 13503-13509. doi: 10.1128/JVI.02148-14

Pfefferkorn, C., Kallfass, C., Lienenklaus, S., Spanier, J., Kalinke, U., Rieder, M., et al. (2016). Abortively infected astrocytes appear to represent the main source of interferon beta in the virus-infected brain. J. Virol. 90, 2031-2038. doi: 10.1128/JVI.02979-15

Pham, A. M., Santa Maria, F. G., Lahiri, T., Friedman, E., Marie, I. J., and Levy, D. E. (2016). PKR transduces MDA5-dependent signals for type I IFN induction. PLoS Pathog. 12:e1005489. doi: 10.1371/journal.ppat.1005489

Pichlmair, A., Schulz, O., Tan, C. P., Naslund, T. I., Liljestrom, P., Weber, F., et al. (2006). RIG-I-mediated antiviral responses to single-stranded RNA bearing 5'-phosphates. Science 314, 997-1001. doi: 10.1126/science.1132998

Pichlmair, A., Schulz, O., Tan, C. P., Rehwinkel, J., Kato, H., Takeuchi, O., et al. (2009). Activation of MDA5 requires higher-order RNA structures generated during virus infection. J. Virol. 83, 10761-10769. doi: 10.1128/JVI.00770-09

Poblete-Duran, N., Prades-Perez, Y., Vera-Otarola, J., Soto-Rifo, R., and ValienteEcheverria, F. (2016). Who regulates whom? An overview of RNA granules and viral infections. Viruses 8:E180. doi: 10.3390/v8070180

Porter, F. W., Bochkov, Y. A., Albee, A. J., Wiese, C., and Palmenberg, A. C. (2006). A picornavirus protein interacts with Ran-GTPase and disrupts nucleocytoplasmic transport. Proc. Natl. Acad. Sci. U.S.A. 103, 12417-12422. doi: 10.1073/pnas.0605375103

Porter, F. W., Brown, B., and Palmenberg, A. C. (2010). Nucleoporin phosphorylation triggered by the encephalomyocarditis virus leader protein 
is mediated by mitogen-activated protein kinases. J. Virol. 84, 12538-12548. doi: 10.1128/JVI.01484-09

Psalla, D., Psychas, V., Spyrou, V., Billinis, C., Papaioannou, N., and Vlemmas, I. (2006). Pathogenesis of experimental encephalomyocarditis: a histopathological, immunohistochemical and virological study in rats. J. Comp. Pathol. 134, 30-39. doi: 10.1016/j.jcpa.2005.06.008

Ricour, C., Delhaye, S., Hato, S. V., Olenyik, T. D., Michel, B., Van Kuppeveld, F. J., et al. (2009). Inhibition of mRNA export and dimerization of interferon regulatory factor 3 by Theiler's virus leader protein. J. Gen. Virol. 90, 177-186. doi: 10.1099/vir.0.005678-0

Rothenfusser, S., Goutagny, N., Diperna, G., Gong, M., Monks, B. G., Schoenemeyer, A., et al. (2005). The RNA helicase Lgp2 inhibits TLRindependent sensing of viral replication by retinoic acid-inducible gene-I. J. Immunol. 175, 5260-5268. doi: 10.4049/jimmunol.175. 8.5260

Satoh, T., Kato, H., Kumagai, Y., Yoneyama, M., Sato, S., Matsushita, K., et al. (2010). LGP2 is a positive regulator of RIG-I- and MDA5-mediated antiviral responses. Proc. Natl. Acad. Sci. U.S.A. 107, 1512-1517. doi: 10.1073/pnas. 0912986107

Schulz, O., Pichlmair, A., Rehwinkel, J., Rogers, N. C., Scheuner, D., Kato, H., et al. (2010). Protein kinase R contributes to immunity against specific viruses by regulating interferon mRNA integrity. Cell Host Microbe 7, 354-361. doi: $10.1016 /$ j.chom.2010.04.007

Sorgeloos, F., Jha, B. K., Silverman, R. H., and Michiels, T. (2013). Evasion of antiviral innate immunity by Theiler's virus $L^{*}$ protein through direct inhibition of RNase L. PLoS Pathog. 9:e1003474. doi: 10.1371/journal.ppat.1003474

Sugimoto, N., Mitoma, H., Kim, T., Hanabuchi, S., and Liu, Y. J. (2014). Helicase proteins DHX29 and RIG-I cosense cytosolic nucleic acids in the human airway system. Proc. Natl. Acad. Sci. U.S.A. 111, 7747-7752. doi: 10.1073/pnas. 1400139111

Sun, Q., Sun, L., Liu, H. H., Chen, X., Seth, R. B., Forman, J., et al. (2006). The specific and essential role of MAVS in antiviral innate immune responses. Immunity 24, 633-642. doi: 10.1016/j.immuni.2006.04.004

Takashima, K., Oshiumi, H., Takaki, H., Matsumoto, M., and Seya, T. (2015). RIOK3-mediated phosphorylation of MDA5 interferes with its assembly and attenuates the innate immune response. Cell Rep. 11, 192-200. doi: 10.1016/j. celrep.2015.03.027

van Eyll, O., and Michiels, T. (2000). Influence of the Theiler's virus L* protein on macrophage infection, viral persistence, and neurovirulence. J. Virol. 74, 9071-9077. doi: 10.1128/JVI.74.19.9071-9077.2000

van Pesch, V., Van Eyll, O., and Michiels, T. (2001). The leader protein of Theiler's virus inhibits immediate-early alpha/beta interferon production. J. Virol. 75, 7811-7817. doi: 10.1128/JVI.75.17.7811-7817.2001

Venkataraman, T., Valdes, M., Elsby, R., Kakuta, S., Caceres, G., Saijo, S., et al. (2007). Loss of DExD/H box RNA helicase LGP2 manifests disparate antiviral responses. J. Immunol. 178, 6444-6455. doi: 10.4049/jimmunol.178.10.6444

Wang, J. P., Cerny, A., Asher, D. R., Kurt-Jones, E. A., Bronson, R. T., and Finberg, R. W. (2010). MDA5 and MAVS mediate type I interferon responses to coxsackie B virus. J. Virol. 84, 254-260. doi: 10.1128/JVI.00631-09

Wente, S. R., and Rout, M. P. (2010). The nuclear pore complex and nuclear transport. Cold Spring Harb. Perspect. Biol. 2:a000562. doi: 10.1101/cshperspect. a000562

White, J. P., and Lloyd, R. E. (2012). Regulation of stress granules in virus systems. Trends Microbiol. 20, 175-183. doi: 10.1016/j.tim.2012.0 2.001

Wies, E., Wang, M. K., Maharaj, N. P., Chen, K., Zhou, S., Finberg, R. W., et al. (2013). Dephosphorylation of the RNA sensors RIG-I and MDA5 by the phosphatase PP1 is essential for innate immune signaling. Immunity 38, 437-449. doi: 10.1016/j.immuni.2012.11.018
Yamamoto, M., Sato, S., Hemmi, H., Hoshino, K., Kaisho, T., Sanjo, H., et al. (2003). Role of adaptor TRIF in the MyD88-independent toll-like receptor signaling pathway. Science 301, 640-643. doi: 10.1126/science.1087262

Yang, X., Hu, Z., Fan, S., Zhang, Q., Zhong, Y., Guo, D., et al. (2018). Picornavirus $2 \mathrm{~A}$ protease regulates stress granule formation to facilitate viral translation. PLoS Pathog. 14:e1006901. doi: 10.1371/journal.ppat.1006901

Yang, Y. L., Reis, L. F., Pavlovic, J., Aguzzi, A., Schafer, R., Kumar, A., et al. (1995). Deficient signaling in mice devoid of double-stranded RNA-dependent protein kinase. EMBO J. 14, 6095-6106. doi: 10.1002/j.1460-2075.1995.tb00300.x

Yarbrough, M. L., Mata, M. A., Sakthivel, R., and Fontoura, B. M. (2014). Viral subversion of nucleocytoplasmic trafficking. Traffic 15, 127-140. doi: 10.1111/ tra. 12137

Yoneyama, M., Kikuchi, M., Matsumoto, K., Imaizumi, T., Miyagishi, M., Taira, K., et al. (2005). Shared and unique functions of the DExD/H-box helicases RIG-I, MDA5, and LGP2 in antiviral innate immunity. J. Immunol. 175, 2851-2858. doi: 10.4049/jimmunol.175.5.2851

Zell, R., Delwart, E., Gorbalenya, A. E., Hovi, T., King, A. M. Q., Knowles, N. J., et al. (2017). ICTV virus taxonomy profile: picornaviridae. J. Gen. Virol. 98, 2421-2422. doi: 10.1099/jgv.0.000911

Zhang, P., Li, Y., Xia, J., He, J., Pu, J., Xie, J., et al. (2014). IPS-1 plays an essential role in dsRNA-induced stress granule formation by interacting with PKR and promoting its activation. J. Cell Sci. 127, 2471-2482. doi: 10.1242/jcs.139626

Zhao, L., Jha, B. K., Wu, A., Elliott, R., Ziebuhr, J., Gorbalenya, A. E., et al. (2012). Antagonism of the interferon-induced OAS-RNase L pathway by murine coronavirus ns2 protein is required for virus replication and liver pathology. Cell Host Microbe 11, 607-616. doi: 10.1016/j.chom.2012.04.011

Zhou, A., Paranjape, J., Brown, T. L., Nie, H., Naik, S., Dong, B., et al. (1997). Interferon action and apoptosis are defective in mice devoid of 2,5'oligoadenylate-dependent RNase L. EMBO J. 16, 6355-6363. doi: 10.1093/ emboj/16.21.6355

Zhou, A., Paranjape, J. M., Hassel, B. A., Nie, H., Shah, S., Galinski, B., et al. (1998). Impact of RNase L overexpression on viral and cellular growth and death. J. Interferon Cytokine Res. 18, 953-961. doi: 10.1089/jir.1998.18.953

Zhu, Q., Tan, P., Li, Y., Lin, M., Li, C., Mao, J., et al. (2018). DHX29 functions as an RNA co-sensor for MDA5-mediated EMCV-specific antiviral immunity. PLoS Pathog. 14:e1006886. doi: 10.1371/journal.ppat.1006886

Zoll, J., Erkens Hulshof, S., Lanke, K., Verduyn Lunel, F., Melchers, W. J., Schoondermark-Van De Ven, E., et al. (2009). Saffold virus, a human Theiler'slike cardiovirus, is ubiquitous and causes infection early in life. PLoS Pathog. 5:e1000416. doi: 10.1371/journal.ppat.1000416

Zoll, J., Galama, J. M., Van Kuppeveld, F. J., and Melchers, W. J. (1996). Mengovirus leader is involved in the inhibition of host cell protein synthesis. J. Virol. 70, 4948-4952.

Zoll, J., Melchers, W. J., Galama, J. M., and Van Kuppeveld, F. J. (2002). The mengovirus leader protein suppresses alpha/beta interferon production by inhibition of the iron/ferritin-mediated activation of NF-kappa B. J. Virol. 76, 9664-9672. doi: 10.1128/JVI.76.19.9664-9672.2002

Conflict of Interest Statement: The authors declare that the research was conducted in the absence of any commercial or financial relationships that could be construed as a potential conflict of interest.

Copyright (®) 2018 Freundt, Drappier and Michiels. This is an open-access article distributed under the terms of the Creative Commons Attribution License (CC BY). The use, distribution or reproduction in other forums is permitted, provided the original author(s) and the copyright owner(s) are credited and that the original publication in this journal is cited, in accordance with accepted academic practice. No use, distribution or reproduction is permitted which does not comply with these terms. 